\title{
Controle da fusariose (Fusarium solani f. sp. piperis) em pimenta-do-reino cv. Bragantina com extratos brutos aquosos e fungicida
}

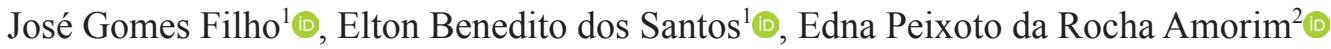

\begin{abstract}
${ }^{1}$ Mestrando do Programa de Pós-graduação em Proteção de Plantas (PPGPP), pela Universidade Federal de Alagoas (UFAL)/Centro de Ciências Agrárias (CECA), CECA/UFAL- BR-104, Km 85 - CEP 57080-000, Rio Largo-AL, Brasil. ${ }^{2}$ Universidade Federal de Alagoas - Centro de Ciências Agrárias (CECA/UFAL), CECA/UFAL- BR-104, Km 85 - CEP 57080-000, Rio Largo-AL, Brasil

Autor para correspondência: José Gomes Filho (jgffilho@gmail.com)
\end{abstract}

Data de chegada: 12/07/2018. Aceito para publicação em: 14/10/2019.

$10.1590 / 0100-5405 / 188781$

\section{RESUMO}

Gomes Filho, J.; Santos, E.B.; Amorim, E.P.R. Controle da fusariose (Fusarium solani f. sp. piperis) em pimenta-do-reino cv. Bragantina com extratos brutos aquosos e fungicida. Summa Phytopathologica, v.46, n.1, p.49-52, 2020.

A fusariose ou podridão-das-raízes, principal doença na pimenteira-doreino, causa severa limitação na produção, provocada pelo fungo (Fusarium solani $\mathrm{f}$. sp. piperis). O objetivo desse trabalho foi avaliar o efeito de extratos brutos aquosos e fungicida no controle da fusariose em pimenta-do-reino. Foi avaliado a porcentagem de inibição micelial de $F$. solani em placas de Petri com meio BDA suplementado com extratos brutos aquosos de folhas (EBA) de pimenta-do-reino, mandioca, mamona, coentro e melão-de-são caetaneo, nas concentrações de 5, 10, 15 e 20\% (v/v). A testemunha foi placa com meio BDA sem adição de produto. Para avaliação do efeito dos extratos sobre o desenvolvimento da fusariose, mudas de pimenta-do-reino foram inoculadas com o patógeno, sendo aspergidas com $20 \mathrm{~mL}$ dos extratos brutos aquosos de melão-de-são caetano e mandioca nas concentrações de 10 e $15 \%$. O fungicida carbendazem foi pincelado no caules das plantas em forma de pasta na dose $\left(0,2\right.$ g. $\left.100 \mathrm{~mL}^{-1}\right)$. A avaliação da incidência da doença foi realizada aos 30 dias após a inoculação. Os resultados mostraram que os extratos de melão-desão caetano e mandioca nas concentrações de 10 e 15\%, proporcionaram os maiores percentuais de inibição micelial (61,01 e 57,61\% e 51,55 e 55,48\%) respectivamente. O EBA de melão-de-são caetano na concentração de $15 \%$ e o fungicida foram eficientes em reduzirem a incidência da fusariose em mudas de pimenta-do-reino.

Palavras-chave: Piper nigrum, produto natural, controle de doença fungica.

\section{ABSTRACT}

Gomes Filho, J.; Santos, E.B.; Amorim, E.P.R. Control of root rot (Fusarium solani f. sp. piperis) in black pepper cv. Bragantina with crude aqueous extracts and fungicide. Summa Phytopathologica, v.46, n.1, p.49-52, 2020.

Fusarium or root rot, the main disease affecting black pepper, leads to severe production limitation caused by the fungus (Fusarium solani f. sp. piperis). The objective of this study was to evaluate the effect of crude aqueous extracts and fungicide on the control of fusariosis in black pepper. The percentage of $F$. solani mycelial inhibition in Petri dishes with PDA medium supplemented with crude aqueous leaf extracts (EBA) of black pepper, cassava, castor bean, coriander and bitter melon were evaluated at the concentrations 5, 10, 15 and 20\% (v/v). Control was the plate containing PDA medium without addition of any product. To evaluate the effect of extracts on the development of fusariosis, black pepper seedlings were inoculated with the pathogen and sprayed with $20 \mathrm{~mL}$ crude aqueous extracts of bitter melon and cassava at the concentrations 10 and $15 \%$. The fungicide carbendazim was brushed as paste on the stems of plants at one dose $\left(0.2 \mathrm{~g} .100 \mathrm{~mL}^{-1}\right)$. The disease incidence was evaluated 30 days after inoculation. Results showed that the extracts of bitter melon and cassava at the concentrations 10 and $15 \%$ provided the highest percentages of mycelial inhibition (61.01 and $57.61 \%$ and 51.55 and $55.48 \%$, respectively). The EBA of bitter melon at the concentration of $15 \%$ and the fungicide were efficient in reducing fusariosis incidence in black pepper seedlings.

Keywords: Piper nigrum, natural product, fungal disease control.

A pimenta-do-reino (Piper nigrum L.), cultura de exploração milenar é uma das especiarias mais importante e consumida mundialmente. Amplamente utilizada como condimento no preparo e em processamento de alimentos (7). A produção da pimenteira-doreino, no Brasil, vem sendo comprometida e limitada, principalmente por problemas de fitossanidade que causam danos as lavouras e perdas na produção (2).

A fusariose ou podridão-das-raízes (Fusarium solani f. sp. piperis Albuq.) é a principal doença da cultura, restrita ao Brasil e vem causando a redução de vida útil das pimenteiras nas regiões produtoras (6). A doença pode reduzir o período útil de exploração da cultura para apenas quatro anos (1).

Trata-se de uma doença de difícil controle, nenhuma cultivar é resistente ou tolerante ao fitopatógeno e não há nenhuma medida eficiente de controle, sendo adotadas apenas medidas preventivas. A utilização de produtos naturais no controle de doenças de plantas representa uma alternativa eficiente no controle de doenças (10). Assim, o objetivo deste trabalho foi avaliar o efeito dos extratos brutos aquosos de pimenta-do-reino ( $P$. nigrum L.), mandioca (Manihot esculenta Crantz), mamona (Ricinus communis L.), coentro (Coriandrum sativum L.) e melão-de-são caetano (Mormodica charantia L.) no controle da fusariose em mudas de pimenta-do-reino cv. bragantina. 
Os experimentos foram conduzidos no Laboratório de Fitopatologia e em casa de vegetação no Centro de Ciências Agrárias (CECA) da Universidade Federal de Alagoas (UFAL), em Rio Largo - AL, no período de junho de 2016 a junho de 2017.

O isolado de Fusarium solani foi obtido a partir de plantas com sintomas da fusariose no município de Atalaia - AL. Para o isolamento de Fusarium solani, empregou-se o meio de cultura batata-dextroseágar (BDA) e incubadas por sete dias a temperatura de $28^{\circ} \mathrm{C}$ com fotoperíodo de 12 horas. Após a confirmação do agente causal, o isolado foi preservado pelo método Castellani em temperatura ambiente.

Os extratos brutos aquosos (EBA) foram adicionados ao meio de cultura BDA, fundente $\left(45-50^{\circ} \mathrm{C}\right)$ em placa de Petri de $9 \mathrm{~cm}$ de diâmetro. Foram testados extratos de folhas de pimenta-do-reino, mandioca, mamona, coentro e melão-de-são caetano, nas concentrações de $5,10,15$ e $20 \%(\mathrm{v} / \mathrm{v})$ e a testemunha (BDA). Todos os tratamentos foram filtrados em gazes tripla esterilizada e esterilizados em luz UV por 1 (h) antes de serem adicionados ao meio autoclavado. No centro de cada placa de Petri foi depositado um disco de BDA com crescimento micelial do patógeno de $5 \mathrm{~mm}$ de diâmetro. Após dez dias de incubação à temperatura de $28^{\circ} \mathrm{C}$ e fotoperíodo de 12 horas, foi determinado o crescimento micelial, medindo-se diariamente em dois sentidos diametralmente opostos, que em comparação com testemunha, avaliouse a porcentagem de inibição do crescimento micelial (P.I.C), conforme a equação proposta por Edginton et al. (3). O delineamento experimental utilizado foi o inteiramente casualizado em esquema fatorial $(5 \times 4)$ +1 com cinco extratos brutos aquosos e quatro concentrações, mais a testemunha com seis repetições. Os dados obtidos foram submetidos a análise de variância e de regressão e as médias comparadas pelo teste de Tukey $(P<0,05)$. Na avaliação do efeito curativo dos extratos vegetais e do fungicida sobre o desenvolvimento da doença, mudas de pimenta-do-reino com seis meses de idade foram transplantadas para vasos com capacidade de $1 \mathrm{~L}$, contendo solo mais o substrato na proporção $1: 4(\mathrm{v} / \mathrm{v})$, previamente autoclavado $\left(1 \mathrm{~atm}, 120^{\circ} \mathrm{C}\right.$ por $2 \mathrm{~h}$ ) e inoculadas com o patógeno, através da técnica de deposição de disco de micélio $(5 \mathrm{~mm})$ em ferimentos realizados com um pequeno corte transversal, no caule das mudas, com o auxílio de um bisturi. Dez dias após a inoculação, as mudas foram tratadas em intervalos de oito dias com cinco aplicações dos produtos (melão-de-são caetano e mandioca, nas concentrações de 10 e 15\%), aplicando-se $20 \mathrm{~mL}$ da solução por planta, adicionados $0,1 \mathrm{~mL}$ do espalhante adesivo Tween 20 (polioxyethylene sobitan mono-oleate) para cada $100 \mathrm{~mL}$ da solução.
As aplicações foram realizadas com pulverizador manual de pressão, espalhando os produtos até o ponto de escorrimento na superfície das folhas. A testemunha recebeu apenas discos de micélio do patógeno. Para o tratamento das mudas com o fungicida (Carbendazim 0,2 g/100 $\mathrm{mL}$ ) foi feito um corte vertical no colo da planta, aplicando-se o produto em forma de consistência pastosa com o auxílio de um pincel, de acordo com a metodologia proposta por Santos (9). A porcentagem de plantas infectadas foi avaliada 30 dias após as aplicações.

Observa-se que houve interação significativa $(\mathrm{p}<0,01)$ dos extratos brutos aquosos sob as diferentes concentrações, na inibição do crescimento micelial de F. solani, indicando que essa variável depende da concentração. As variáveis foram desdobradas para EBA dentro de cada concentração, conforme a Tabela 1. Para a inibição do crescimento micelial em função das concentrações usadas para cada EBA, aplicou-se regressão. O EBA de melão-de-são caetano e mandioca, nas concentrações de 10 e $15 \%$ proporcionaram uma inibição de 51,$53 ; 55,48 ; 61,01$ e $57.61 \%$, respectivamente. Enquanto os extratos de pimenta-do-reino e coentro as inibições foram de 38,4; 59,33; 24,56 e $22,73 \%$, nessas concentrações. Verifica-se que, na concentração de $15 \%$, o extrato de pimenta-do-reino não diferiu dos extratos de mandioca e melão-de-são caetano. Os EBA de mamona e coentro foram os que proporcionaram as menores PIC, em todas as concentrações testadas.

Os resultados desse estudo indicam a eficiência dos extratos vegetais de mandioca e melão-de-são caetano no desenvolvimento "in vitro" de Fusarium solani em pimenta-do-reino. Vidal (11), avaliando o efeito "in vitro" de extrato de melão-de-são caetano sobre o crescimento micelial de C. gloeosporioides, observou uma inibição micelial de $74,5 \%$ na concentração de $1500 \mu \mathrm{g} . \mathrm{mL}^{-1}$ e Ferreira (4), que ao avaliar o efeito de diferentes concentrações de extrato aquoso de mandioca sobre F. oxysporum f. sp. passiflorae, na concentração de $10 \%$ obteve o maior potencial de inibição de crescimento micelial. Rodrigues et al. (8), avaliando o efeito de hidrolatos de Coriandrum sativum sobre o desenvolvimento de Phytophthora sp., nas concentrações de 10 e 15\%, verificaram uma inibição micelial de 45,05 e 66,24\%, respectivamente. Harish et al. (5), estudando a atividade antifúngica de extratos aquosos de sementes de mamona, verificaram uma inibição do crescimento micelial de 55,68\% de Helminthosporium oryzae.

De acordo com as análises de regressão na Figura 1, observa-se que todas as concentrações testadas apresentam efeitos significativos sobre a PIC do patógeno. O modelo de regressão que mais se adequou foi o quadrático para as concentrações dos extratos de pimenta-do-reino,

Tabela 1. Efeito da interação dos extratos brutos aquosos (EBA) de pimenta-do-reino, mandioca, mamona, melão-de-são caetano e coentro sob diferentes concentrações na porcentagem de inibição do crescimento micelial (PIC) de Fusarium solani.

\begin{tabular}{|c|c|c|c|c|}
\hline EBA & \multicolumn{4}{|c|}{ Concentrações } \\
\hline Pimenta-do-reino & $20,56 \mathrm{c}^{*}$ & $38,40 \mathrm{c}$ & $59,33 \mathrm{a}$ & $55,24 \mathrm{~b}$ \\
\hline Mandioca & $28,90 \mathrm{~b}$ & $51,53 \mathrm{~b}$ & $55,48 \mathrm{a}$ & $66,57 \mathrm{a}$ \\
\hline Mamona & $6,92 \mathrm{~d}$ & $19,81 \mathrm{~d}$ & $21,85 \mathrm{~b}$ & $33,87 \mathrm{c}$ \\
\hline Coentro & $13,83 \mathrm{~cd}$ & $24,56 \mathrm{~d}$ & $22,73 \mathrm{~b}$ & $54,59 \mathrm{~b}$ \\
\hline CV \% & \multicolumn{4}{|c|}{11,28} \\
\hline
\end{tabular}

*Médias seguidas pela mesma letra minúscula em cada coluna não diferem estatisticamente entre si pelo teste de Tukey ao nível de $5 \%$ de probabilidade. 
mandioca, mamona e coentro, exceto para o extrato de melão-de-são caetano que mostrou-se em equação linear.

Para o extrato bruto aquoso de pimenta-do-reino, com coeficiente de determinação de $99 \%$, observa-se que a partir da concentração de $5 \%$ já apresentam efeitos significativos de inibição do patógeno, porém, os melhores percentuais de inibição micelial foram verificados nas concentrações de 15 e $20 \%$. Para o extrato bruto aquoso de mandioca, o efeito inibitório do patógeno foi observado a partir da concentração de $5 \%$ e verifica-se o aumento do percentual de inibição micelial em função do aumento das concentrações testadas, com coeficiente de determinação de $99 \%$.

Nota-se que o extrato bruto aquoso de mamona apresentou os menores percentuais de inibição do crescimento micelial em todas as concentrações, onde na maior concentração obteve o maior porcentagem de inibição do patógeno, indicando que a redução da colônia fúngica é diretamente proporcional ao aumento da concentração, com coeficiente de determinação de $99 \%$. O extrato bruto aquoso de melão-de-são caetano promoveu uma inibição micelial linear sobre a colônia de Fusarium solani. Verifica-se que houve uma acentuada redução do diâmetro da colônia do patógeno, com inibição acima de $60 \%$ a partir
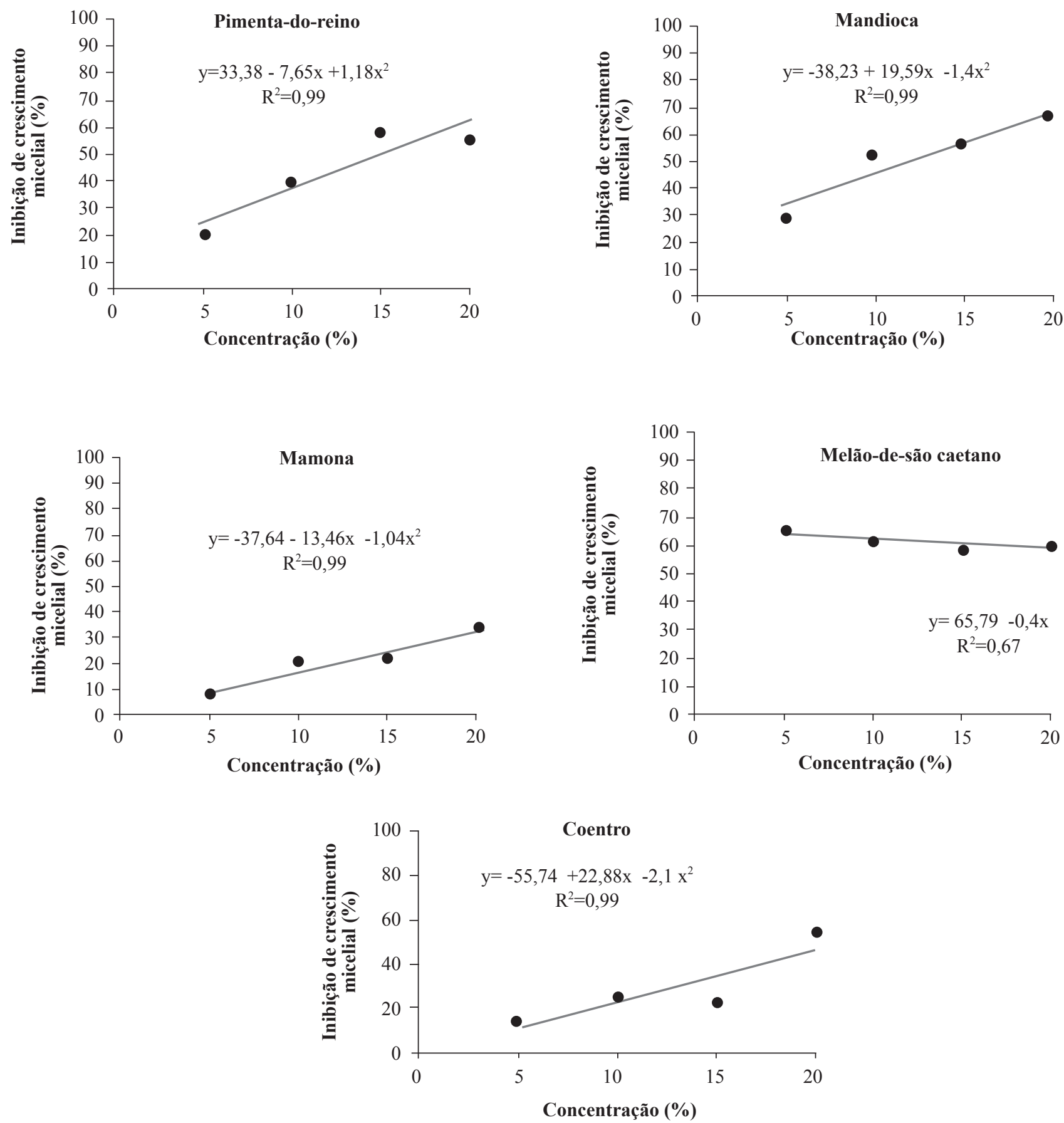

Figura 1. Efeito da concentração de extrato bruto aquoso (EBA) na porcentagem de inibição do crescimento micelial (PIC) de Fusarium solani. 


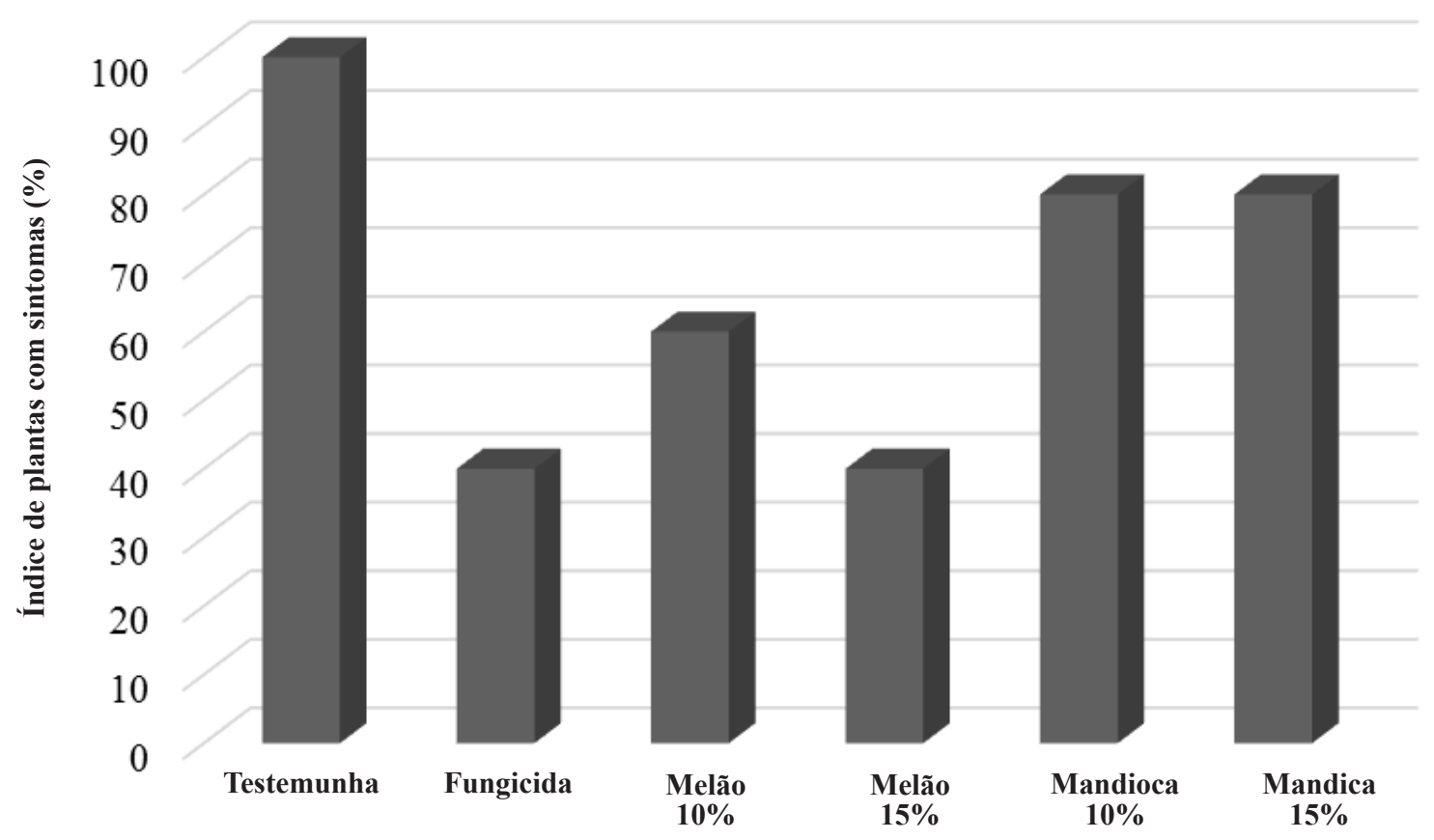

Figura 2. Efeitos de extratos brutos aquosos (EBA) sobre a incidência da fusariose em mudas de pimenta-do-reino.

da concentrações de 5 e 10\%, no entanto, nota-se uma diminuição com o aumento da concentração na porcentagem de inibição do crescimento micelial, apresentando coeficiente de determinação de 67\%. Para o extrato bruto aquoso de coentro, observa-se que a partir da concentração de $10 \%$ já apresenta efeito na inibição do crescimento micelial acima de $20 \%$, chegando atingir mais que o dobro na porcentagem de inibição micelial na maior concentração, com coeficiente de determinação de $99 \%$, demonstrando atividade fungitóxica ao patógeno.

Em relação a incidência da doença, a avaliação foi realizada aos 30 dias após as aplicações dos produtos naturais, conforme a Figura 2. Todos os tratamentos diferiram da testemunha. O EBA de melãode-são caetano na concentração de $15 \%$ proporcionou o menor índice de doença ( $40 \%$ ), não diferindo do fungicida, configurando, portanto, o melhor tratamento, seguido do melão de são caetano $10 \%$, cuja incidência de doença foi de $60 \%$. As concentrações de 10 e $15 \%$ do EBA de mandioca não diferiram entre si, proporcionando um alto índice de doença (80\%). A eficiência do extrato bruto aquoso EBA do melão-de-são caetano na maior concentração, deve-se possivelmente as suas substâncias bioativas presentes que possuem ação antifúngica, tais como alcaloides, flavonoides, saponinas, glicosídeos.

Conforme os dados obtidos no presente trabalho, conclui-se que o EBA de melão-de-são caetano na concentração a partir de $15 \%$ apresenta uma possibilidade para o controle alternativo da fusariose em pimenteira-do-reino cv. Bragantina. Porém, mais estudos são necessários para elucidar e melhorar o aproveitamento desse EBA no controle da doença.

\section{REFERÊNCIAS}

1. Carnauba, J.P.; Sobral, M.F.; Amorim, E.P.R.; Silva, I.O. Ocorrência de Fusarium solanif. sp. Piperis em piper nigrum no estado de Alagoas. Summa Phytopatológica, Botucatu, v.33, n.1, p.96-97, 2007.
2. Drumond Neto, A.P. Distribuição espacial e correlação da incidência de fusariose em pimenta-do-reino com atributos do solo. 2012. 70f. Dissertação (Mestrado em Agricultura Tropical) - Centro Universitário Norte do Espírito Santo, Universidade Federal do Espírito Santo, São Mateus, 2012.

3. Edgington, L.V.; Khew, K.L.; Barron, G.L. Fungitoxic spectrum of bendizidazole compounds. Phytopathology, Ontário, v.61, p.42-44, 1971.

4. Ferreira, R.; Rodrigues, A.; Catarino, A.; Moraes, F. Utilização dos resíduos orgânicos de nim e citronela no controle de Fusarium oxysporum f. sp. passiflorae em maracujazeiro amarelo. Revista Brasileira de Agroecologia, Cruz Alta, v.4, n.2, p.893-896, 2009.

5. Harish, S.; Saravanan, T.; Radjacommare, R.; Ebenezar, E.G.; Seetharaman, K. Mycotoxic effect of seed extracts against Helminthosporium oryzae Breda de Hann, the incitant of ricebrown spot. Journal of Biological Sciences, Coimbatore, v.4, p.366-369, 2004.

6. Lourinho, M.P.; Costa, C.A.S.; Souza, L.C.; Souza, L.C.; Oliveira Neto, C.F. Conjuntura da pimenta-do-reino no mercado nacional e na região Norte do Brasil. Enciclopédia Biosfera, Goiânia, v.10, n.18, p.1016-1031, 2014.

7. Prabhakaran Nair, K.P. Agronomy and economy of black pepper and cardamom: The "King" and "Queen" of Spices. London: Elsevier Science Publishing, 2011. 366p.

8. Rodrigues, M.S.; Jardinetti, V.A.; Schwan-Estrada, K.R.F.; Cruz, M.E.S.; Jesus, L.S. Atividade fungitóxica de hidrolatos de plantas medicinais. Cadernos de Agroecologia, Fortaleza, v. 6, n. 2, nov. 2011. Disponível em: <http://aba-agroecologia.org.br/revistas/index.php/cad/article/ view/12458>. Acesso em: 13 jan. 2017.

9. Santos, D.V. Controle alternativo da podridão seca de caule e raiz de graviola (Anonna muricata L.) causada por Lasiodiplodia theobromae (Pat.) Griffon \& Maubl no estado de Alagoas. 2015. 59f. Dissertação (Mestrado em Produção Vegetal) - Centro de Ciências Agrárias, Universidade Federal de Alagoas, Rio Largo, 2015.

10. Santos, M.Q.C. Caracterização de Pythium Cucurbitacearum, e controle alternativo da podridão do colo e das raízes do mamoeiro, grupo solo, cultivar Golden. 2015. 96f. Tese (Doutorado em Proteção de Plantas) - Centro de Ciências Agrárias, Universidade Federal de Alagoas, Rio Largo, 2015.

11. Vidal, J.M. Controle alternativo da antracnose em frutos de mamoeiro e qualidade pós-colheita. 2014. 34p. Trabalho de Conclusão de Curso (Graduação em Agronomia) - Universidade Federal da Paraíba, Areia, 2013. 